\title{
Embargos de Declaração: Instrumento para Garantir Motivação Decisória
}

\author{
Amendment of Judgement: Instrument to Guarantee the Decisions' Motivation
}

\author{
Michel Ferro e Silva' \\ Leonardo Costa Norat ${ }^{2}$ \\ ${ }^{1}$ Centro Universitário do Pará - CESUPA, Brasil \\ ${ }^{2}$ Universitário Federal do Pará - UFPA, Brasil
}

\begin{abstract}
Resumo
Atualmente, a prática forense tem demonstrado que os debates jurídicos muitas vezes são coibidos por posições defensivas adotadas pelos órgãos julgadores, orientadas a impedir o prosseguimento da discussão através do uso indiscriminado de precedentes, seja na aplicação destes sem a devida técnica, seja em sua invocação para restringir a análise de outros argumentos. A legislação, por outro lado, impõe que todos os fundamentos capazes de infirmar conclusão do juiz sejam aferidos, além de impor o exame dos elementos que tornem compatível eventual precedente a ser invocado, cuja desconformidade com tais previsões, importa na vicissitude decisória. Em razão disso, mediante este breve ensaio, propõe-se refletir sobre a utilização dos embargos de declaração como instrumento para sanar os vícios e propiciar a motivação jurisdicional e a aplicação da técnica de precedentes.
\end{abstract}

Palavras-chave: Embargos de declaração; Motivação decisória; Precedentes.

\begin{abstract}
The current days have been showing that the legal debates many times are limited by defensive positions adopted by the jurisdictional organs, which those are destined to unable the following course of discussions sustained at the unrestricted use of stare decisis, even by applicating them without the correspondent technic or limit the arguments analysis. The legislation, however, determines that all the fundaments able to influence the judges' conclusion must be observed and the precedent elements need to be examined, before its application. If the procedure does not follow this way, the decision will be vicious. Because of that, by this succinct essay, is proposed to think about the amendment of judgement as an instrument to correct those vicious and to enable the decisions' motivation and the technic of precedents.
\end{abstract}

Keywords: Amendment of Judgement; Decisions' motivation; Precedents.

\section{Introdução}

O exercício da advocacia enseja uma série de idas e vindas, discussões mais aprofundadas, outras mais rasas, elaborações de teses complexas e outras de evidente resolução. No entanto, hoje, talvez, um de seus maiores desafios não se limite ao debate hermenêutico processual ou, ainda, do convencimento inter partes para lograr êxito na autocomposição, mas, de fato, a luta diária em um sistema judiciário cada vez mais expurgatório e quantitativo, cuja relutância do conteúdo acarreta no próprio afastamento do dever estatal de prestação jurisdicional.

Sem dúvidas, o abarrotamento do Poder Judiciário é um dos fatores preponderantes para a assunção deste estado de latência da discussão jurídica no âmbito processual. Afinal, como identificado 
no relatório "justiça em números" do Conselho Nacional de Justiça (CNJ), identificou-se haver no país, em 2017, 80,1 milhões de processos em tramitação (CNJ, 2018).

É lógico que mecanismos judicantes devem ser criados e aperfeiçoados para atender demandas tão massificadas. Por outro lado, não se podem deixar ao relento demandas que exigem maiores observações. Com fulcro nisto, faz-se preponderante retornar alguns passos e ressaltar aspectos tão caros ao exercício da advocacia e à própria excelência da oferta de soluções pelo Judiciário.

Há de se escalar a pirâmide que se extrai do pensamento de Kelsen (1987) até chegarmos à Constituição de 1988, para, ali, então, encontrarmos a resposta para a superação do problema da mecanização da discussão jurídica.

Com efeito, necessário se ater, acreditamos, a dois primados fulcrais propugnados pela Carta de 88. O primeiro, da inafastabilidade da justiça, elencada no artigo $5^{\circ}$, inciso XXXV, que encontra morada na atuação monopolista estatal da jurisdição", cuja existência remonta à proibição da "justiça de mão própria" (MIRANDA, 2016, p. 278, grifos do original), cabendo ao Estado responder satisfatoriamente àqueles que o procuram.

Destaque-se, no mais, o dever de motivação, estabelecido no art. 93, inciso IX, que, complementarmente ao dispositivo supracitado, tem a função de tutelar o jurisdicionado à melhor solução de seu conflito.

Todavia, abrangentes que são, tais orientações constitucionais clamam por instrumentos que garantam sua eficácia. Dentre estes - e aqui reside o escopo-meio deste trabalho - salientamos um mecanismo tão rechaçado pelo Judiciário: os embargos de declaração.

Tal recurso, previsto no art. 1.022, do Código de Processo Civil (CPC), ao que nos cabe neste introito indicar, se destina ao saneamento de vícios decorrentes justamente do afastamento da jurisdição ao seu dever de motivação, quando proferida decisão obscura, contraditória, omissa ou que contenha erro material.

Sua função, na atual norma processual, ao contrário do que dispunha o Código de Processo Civil de 1973 (CPC/73), foi expandida ao englobar vícios também elencados no art. 489, §1º , do CPC, dos quais, nos deteremos a tratar daqueles previstos nos incisos IV e VI, que cuidam, respectivamente da ausência de enfrentamento decisório de "todos os argumentos deduzidos no processo capazes de, em tese, infirmar a conclusão adotada pelo julgador" e de observância de "enunciado de súmula, jurisprudência ou precedente invocado pela parte, sem demonstrar a existência de distinção no caso em julgamento ou a superação do entendimento”.

\section{Inafastabilidade da jurisdição e dever de motivação}

Conforme salientado anteriormente, a inafastabilidade da jurisdição remonta ao momento em que o Estado assume o papel de terceiro isento que, impedindo vindita, e amparado pelo próprio consenso social de que cabe a ele o melhor juízo valorativo sobre os conflitos intersubjetivos, decidirá tais litígios da melhor maneira, dando uma resposta contundente ao jurisdicionado.

Frise-se que o intuito não está em decidir favorável ao que se pede, mas, sobretudo, resolver o que se pleiteia. Não por menos, o legislador processual de 2015 materializou tal valor de maneira bastante evidente, ao destacar a primazia do mérito no art. $4^{\circ}$ ("solução integral do mérito") ${ }^{2}$ e as possibilidades de aplicação da fungibilidade recursal ${ }^{3}$.

1 Tal monopólio, contudo, importa destacar, comporta flexões, como, por exemplo, a outorga às partes elegerem juízo arbitral.

2 Art. $4^{\circ}$ As partes têm o direito de obter em prazo razoável a solução integral do mérito, incluída a atividade satisfativa.

3 Dentre outros dispositivos, cite-se o parágrafo terceiro do artigo 1.024, CPC: “§ $3^{\circ}$ O órgão julgador conhecerá dos embargos de declaração como agravo interno se entender ser este o recurso cabível, desde que determine previamente 
Acerca de tais questões, o Fórum Permanente de Processualistas Civis elaborou enunciados que reforçam suas aplicabilidades. Sobre a fungibilidade, o de número $104^{4}$ e quanto à primazia do mérito, o de número $372^{5}$.

Sendo assim, no que tange a este ponto, há de se ter em mente que não se afastar da prestação jurisdicional não significa tão somente responder o problema, mas solucioná-lo.

De modo diverso, mas suplementar, o dever de motivação das decisões judiciais é, para além de fim, meio de satisfação dos pleitos jurisdicionais. Ora, não adianta dizer quem tem ou não direito de algo. É necessário se chegue a esta conclusão através de meios racionais, isto é, "que o decisum seja acessível por meio da razão" (ALVIM, 2018, n.p.), permitindo que a parte saiba terem sido suas razões analisadas, bem como, demonstrando que estas o foram de modo isonômico.

Em consonância, bem dissertam Carlos Cordeiro e Josiane Gomes (2018, p. 117) ao destacar que "seria contraditório assegurar o direito de ação e o direito de defesa e as alegações e provas colacionadas aos autos pelas partes não precisassem ser obrigatoriamente analisadas pelo magistrado no momento da decisão".

Nesse sentido, ao mesmo tempo em que a Constituição impõe um dever ao estado, há, em contrapartida, o direito do jurisdicionado a obter uma decisão fundamentada. Não por menos, o CPC/ 15 tratou de instrumentalizar tal direito individual através dos artigos 489, \$1 ${ }^{\circ}$ e 1.022, cuja advinda ao mundo jurídico serve de acessório ao interesse jurídico a ser tutelado (CANOTILHO, 1993).

Para além da função instrumental, reside ainda no dever de motivação, a função legitimadora. Sobre a matéria, sem retoques são os ensinamentos do Ministro Celso de Mello ao gravar no julgamento do HC 80.892 que:

A fundamentação constitui pressuposto de legitimidade das decisões judiciais. A fundamentação dos atos decisórios qualifica-se como pressuposto constitucional de validade e eficácia das decisões emanadas do Poder Judiciário. A inobservância do dever imposto pelo art. 93, IX, da Carta Política, precisamente por traduzir grave transgressão de natureza constitucional, afeta a legitimidade jurídica da decisão e gera, de maneira irremissível, a consequente nulidade do pronunciamento judicial (SUPREMO TRIBUNAL FEDERAL, 2016, p. 821).

Destaque-se, além disso, que a força deste direito constitucionalmente previsto na Constituição - partindo-se de uma interpretação contemporânea dela - por si só já é fonte para tutela estatal, pois não necessitaria de outros meios para sua consecução, mas está permeado de imperatividade a ser externalizada no mundo dos fatos, superando a idealidade normativa e conectando o dever ser ao ser, presente na realidade social (BARROSO, 2018).

Portanto, localizadas no ápice piramidal as fontes axiológicas, faz-se pertinente, então, passar ao estudo dos instrumentos postos na norma infraconstitucional, de modo especial, sobre o dever motivar as decisões perante as razões de convencimento trazidas pelas partes, bem como acerca da inobservância de precedentes eventualmente invocados.

\section{Generalidades dos embargos de declaração}

Previstos no art. 1.022, do CPC, os embargos de declaração poderão ser opostos nos casos em que forem proferidas decisões obscuras, contraditórias (inciso I), omissas (II) ou contidas de erro material (III).

a intimação do recorrente para, no prazo de 5 (cinco) dias, complementar as razões recursais, de modo a ajustá-las às exigências do art. 1.021, $\S 1^{0}$ ”.

4 Enunciado 104: "O princípio da fungibilidade recursal é compatível com o CPC e alcança todos os recursos, sendo aplicável de ofício”. (Grupo: Ordem dos Processos no Tribunal, Teoria Geral dos Recursos, Apelação e Agravo).

$5 \quad$ Enunciado 372: "O art. 4ºm tem aplicação em todas as fases e em todos os tipos de procedimento, inclusive em incidentes processuais e na instância recursal, impondo ao órgão jurisdicional viabilizar o saneamento de vícios para examinar o mérito, sempre que seja possível a sua correção". (Grupo: Normas fundamentais). 
Considera-se obscura a decisão que "careça de elementos que o organize e lhe confira harmonia interpretativa” (DIDIER JR.; CUNHA, 2017, p. 295), ou seja, é a decisão cuja estrutura semântica não permite que a parte identifique quais os fundamentos nela contidos que ensejaram a conclusão lógica ali propugnada. Costuma-se citar como exemplo a decisão repleta de termos em língua estrangeira ou aquela que, feita à mão, não se consegue entender.

Contraditória será a decisão que não tem decorrência lógica daquilo utilizado como razão para conclusão infirmada.

Diz-se haver erro material no pronunciamento judicial quando por erro de digitação, menção errônea de nome, números, dados, facilmente verificáveis. Pode-se discutir, especificamente neste ponto, se equívocos na observação de documentos levados ao processo podem configurar ou não erro material.

Em tal caso, poder-se-ia debater se os erros implicariam ou não na modificação do conteúdo decisório. Pode-se invocar, por exemplo, o caso em que, discutindo-se incompetência por motivo de foro entre as cidades X e Y, o juízo, verificando erroneamente os documentos acostados aos autos, nomeia como competente o foro de Z. É palpável justificar a defesa através dos embargos de declaração para alteração decisória, principalmente se no corpo da decisão for possível compreender os argumentos aludidos pelo juízo, até mesmo, por força de economia processual.

O erro material é, portanto, o erro a) perceptível por qualquer homo medius; b) e que não tenha, evidentemente, correspondido à intenção do juiz (WAMBIER; 2016, n.p., grifos do original); pressupostos que se evidenciam no exemplo citado.

Por derradeiro, mas não menos importante - ao contrário, talvez o ponto mais relevante - o vício de omissão da decisão judicial se encontrará, nos termos do art. 1.022, parágrafo único, inciso II, naquela que "deixe de se manifestar sobre tese firmada em julgamento de casos repetitivos ou em incidente de assunção de competência aplicável ao caso sob julgamento" ou, ainda, "incorra em qualquer das condutas descritas no art. $489, \S 1^{1}$ ”.

Aqui reside, como, já aventado anteriormente, forte ponto instrumental dos embargos de declaração ao dever de motivação das decisões judiciais.

O inciso um, em trato, dispõe acerca do reforço do sistema de precedentes trazido pelo Código vigente (MITIDIERO, 2017), disposto de maneira mais evidente nos artigos 926 a 928, os quais, sumariamente, tratam do dever dos tribunais em manter sua jurisprudência estável, além de observar, sobretudo, as teses hierarquicamente superiores firmadas. Acresce-se também, embora de modo bastante abrangente, uma espécie de sistemática para alteração das teses já firmadas.

O inciso dois, por sua vez, remete-se ao art. 489, §1º que, sem correspondência no CPC/73, traz de maneira bastante elucidativa quais os elementos necessários dos pronunciamentos judiciais e consigna, de modo patente, que "não se considera fundamentada qualquer decisão judicial, seja ela interlocutória, sentença ou acórdão" a decisão que fira as disposições de seus incisos. Logo, carece de motivação a decisão que "se limitar à indicação, à reprodução ou à paráfrase de ato normativo, sem explicar sua relação com a causa ou a questão decidida" (I); "empregar conceitos jurídicos indeterminados, sem explicar o motivo concreto de sua incidência no caso" (II); "invocar motivos que se prestariam a justificar qualquer outra decisão" (III); "não enfrentar todos os argumentos deduzidos no processo capazes de, em tese, infirmar a conclusão adotada pelo julgador" (IV); "se limitar a invocar precedente ou enunciado de súmula, sem identificar seus fundamentos determinantes nem demonstrar que o caso sob julgamento se ajusta àqueles fundamentos" (V) e "deixar de seguir enunciado de súmula, jurisprudência ou precedente invocado pela parte, sem demonstrar a existência de distinção no caso em julgamento ou a superação do entendimento" (VI).

É possível, ainda, invocar em sede de embargos de declaração, matérias de ordem pública, isto é, aquelas cognoscíveis em qualquer grau de jurisdição, bem como as decisões citra ou infra petita, i.e., decide-se aquém do requerido pela parte. O mesmo não se pode falar das decisões extra ou ultra, petita, recorríveis pela impugnação principal, cuja decisão importará em reduzir-lhe aos limites do pedido (NERY JR; NERY, 2019). 
Resta claro, pelo exposto, que a lei tratou de identificar, de modo pontual, quais as hipóteses em que a oposição de embargos de declaração é pertinente. Isto se deve ao fato de que, conforme classificação doutrinária (DIDIER JR., CUNHA, 2017), tal recurso é de "fundamentação vinculada", o que significa dizer que sua aplicação se dará, tão somente, nas hipóteses previstas - supracitadas -, o que não ocorre, por outro lado, por exemplo, com a apelação ou recurso ordinário, os quais são de "fundamentação ampla". Fato é, no entanto, que o art. 489, \$1º , tratou de ampliar e, até mesmo, aclarar os vícios que ensejariam a omissão no pronunciamento do julgador.

Cabe ainda, dissertar, sumariamente, sobre os efeitos do recurso.

Para tanto, necessário consignar, desde logo, que os embargos de declaração são endereçados diretamente ao juízo que proferiu a decisão vergastada, ou seja, o mesmo órgão jurisdicional que proferiu a decisão será o competente para analisá-los, exercendo, por assim dizer, um duplo grau de jurisdição contido.

No caso dos embargos de declaração lhe são típicos os efeitos devolutivo e interruptivo (art. 1.026, do CPC), sendo, por outro lado, excepcional a concessão, nos termos do art. 1.026, §1 $1^{\circ}$, CPC, de efeito suspensivo, quando a imediata eficácia da decisão puder gerar dano grave ou de difícil reparação e houver fundamento relevante para tanto; não obstante, nos casos em que os declaratórios sejam opostos contra sentença, cuja apelação - recurso principal - possua efeito suspensivo ope legis, a ausência de tal efeito não autoriza o cumprimento provisório ${ }^{6}$.

Quanto ao efeito modificativo, sua hipótese é também exceção posto que, em regra, o recurso não discute a análise da matéria litigada, mas se destina a sanar vícios formais.

Sinalize-se sobre a natureza jurídica da decisão proferida. Esta será a mesma daquela impugnada, o que se dá por consequência do próprio efeito devolutivo ao mesmo órgão jurisdicional, diversamente, por exemplo, do que ocorre com o agravo de instrumento, que, destinado a reformar ou anular decisão interlocutória, será julgado por acórdão, ou, ainda por decisão monocrática do relator, nas hipóteses legalmente permitidas.

Outras duas questões importantes também merecem realce. Uma delas é a possibilidade de fungibilidade dos embargos de declaração em agravo interno (art. 1.024, §3º, do CPC) já mencionada anteriormente.

Sobre a fungibilidade recursal, é possível vê-la como derivada do princípio da instrumentalidade das formas (DIDIER JR.; CUNHA, 2017), a qual, embora não tenha previsão normativa expressa, é por outro lado, aceita por doutrina e jurisprudência e, ao fundo perceptível em certos dispositivos, como o em questão, e será aplicável quando houver dúvida objetiva sobre qual recurso utilizar, incerteza razoável sobre seu cabimento, decisão proferida de natureza diversa e ausência de "erro grosseiro" na interposição (THAMAY; ANDRADE, 2018).

O dispositivo em tela representa um ponto de equilíbrio aos instáveis entendimentos em sede de hermenêutica recursal, cuja consequência é justamente a garantia da coerência à sistemática das impugnações às decisões, o que, permite instrumentalizar o amplo acesso à justiça (JORGE JUNIOR, 2018). Tal previsão também apresenta consonância com o princípio da primazia do mérito, alhures abordada, o que torna como última escolha, a extinção ou nulidade sem resolução do mérito (AURELLI, 2018).

Outra questão importante é a busca do legislador processualista em coibir atuações desleais dos litigantes ao dispor no art. 1.026, nos parágrafos $2^{\circ}, 3^{\circ}$ e $4^{\circ}$, a possibilidade de cominação de multa em caso de reiterada oposição de embargos protelatórios, bem como, a pena de inadmissibilidade de novos embargos quando os dois últimos tiverem sido considerados com o fim procrastinatório, e condicionando a interposição de outro eventual recurso ao depósito da multa imposta.

Sendo assim, realizada breve análise necessária sobre o recurso, é de importância, sobretudo prática, identificar empecilhos que o seu regular andamento do possa encontrar.

6 Em consonância, o Fórum Permanente de Processualistas Civis no enunciado no 218: "A inexistência de efeito suspensivo dos embargos de declaração não autoriza o cumprimento provisório da sentença nos casos em que a apelação tenha efeito suspensivo". 


\section{Jurisprudência defensiva dos tribunais: o problema dos "argumentos capazes de infirmar a conclusão adotada pelo julgador" e a ausência de distinguishing das decisões judiciais.}

No tópico anterior se vislumbrou a hipótese de que o próprio órgão jurisdicional possa rever formalmente sua decisão e, por consequência lógica, reconhecer seu equívoco.

Assumir este erro, contudo, parece, muitas vezes, ser interpretado como afrontoso aos julgadores, o que, acrescido pela má-fé de certos litigantes - para a qual não se podem fechar os olhos - na oposição volumosa de recursos com fins procrastinatórios, enseja uma jurisprudência de cunho estritamente defensivo (VAUGHN, 2018).

O que se percebe, de fato, é a padronização de decisões, principalmente no julgamento de embargos de declaração, que utilizam de jargões jurídicos como "amuletos" (CARBONAR, 2018, p. 1.009) para manter o julgador afastado da análise da questão de fundo tratada na demanda, distanciando-se, por consequência, da primazia do mérito.

Dos argumentos levantados em sede de embargos de declaração, captam-se ao debate dois que, pela prática forense, se mostram ao mesmo tempo os que permitem ampla discussão jurídica, uma vez que demandam a análise de mérito próprio inserido no vício formal da ausência de fundamentação de que tratam, e os que mais sofrem com os pronunciamentos defensivos dos tribunais. Serão analisados em conjunto, a seguir, os incisos IV e VI, do art. 489, §1º , do CPC.

\subsection{As previsões do artigo 489, $\S 1^{\circ}$, IV e VI, do CPC.}

Indica o dispositivo em questão que não será considerada fundamentada a decisão que "não enfrentar todos os argumentos deduzidos no processo capazes de, em tese, infirmar a conclusão adotada pelo julgador" (IV), bem como aquela que "deixar de seguir enunciado de súmula, jurisprudência ou precedente invocado pela parte, sem demonstrar a existência de distinção no caso em julgamento ou a superação do entendimento" (VI) e, por força do art. 1.022, p. único, II, será, portanto, impugnável mediante embargos de declaração.

Sobre o inciso IV, cabe aqui partir de um pressuposto extraível da própria sistemática do Código, para tanto, é possível invocar, como se vem discorrendo neste trabalho, a primazia do mérito, o dever de motivação jurisdicional e a inafastabilidade da jurisdição.

Veja-se que o legislador foi literal ao dispor "todos" os argumentos capazes de infirmar a conclusão do julgador, não dispôs "suficiente" ou "ao menos um".

Pois bem, a resposta jurisprudencial dentre as Cortes locais ${ }^{7}$ e, principalmente, do Superior Tribunal de Justiça, passou a propugnar a ideia de que "o julgador não está obrigado a responder a todas as questões suscitadas pelas partes, quando já tenha encontrado motivo suficiente para proferir a decisão"8.

7 Dos vários julgados encontráveis, citem-se alguns de norte a sul do país: TJ-AP - ED: 00278350920178030001 AP, Relator: Desembargadora SUELI PEREIRA PINI, Data de Julgamento: $07 / 05 / 2019$, Tribunal; TJ-DF 00204875420168070003 DF 0020487-54.2016.8.07.0003, Relator: GETÚLIO DE MORAES OLIVEIRA, Data de Julgamento: 05/06/2019, 7ª Turma Cível, Data de Publicação: Publicado no DJE : 19/06/2019 . Pág.: Sem Página Cadastrada; TJ-SP - EMBDECCV: 20379634720198260000 SP 2037963-47.2019.8.26.0000, Relator: Coimbra Schmidt, Data de Julgamento: 07/04/2012, 7aㅡ Câmara de Direito Público, Data de Publicação: 21/03/2019; TJ-RS - ED: 70081280463 RS, Relator: Luiz Felipe Brasil Santos, Data de Julgamento: 16/05/2019, Oitava Câmara Cível, Data de Publicação: Diário da Justiça do dia 21/05/2019.

8 Conforme voto do Min. Francisco Falcão em: STJ - EDcl na Rcl: 34817 SP 2017/0239457-6, Relator: Ministro FRANCISCO FALCÃO, Data de Julgamento: 22/05/2019, S1 - PRIMEIRA SEÇÃO, Data de Publicação: DJe 04/06/2019. Dentre outros mais, mencionem-se: STJ - EDcl nos EDcl no AgInt nos EDcl no REsp: 1603264 PR 2016/0132675-0, Relator: Ministro FRANCISCO FALCÃO, Data de Julgamento: 07/06/2018, T2 - SEGUNDA TURMA, Data de Publicação: DJe 14/06/2018; STJ - EDcl no AgInt no AREsp: 1196863 DF 2017/0282281-2, Relator: Ministro FRANCISCO FALCÃO, Data de Julgamento: 12/03/2019, T2 - SEGUNDA TURMA, Data de Publicação: DJe 18/03/2019 e STJ - EDcl no AgRg no REsp: 1550142 SP 2015/0201557-0, Relator: Ministra DIVA MALERBI (DESEMBARGADORA CONVOCADA TRF 3를 REÃO), Data de Julgamento: 05/04/2016, T2 - SEGUNDA TURMA, Data de Publicação: DJe 13/04/2016. 
Ora, ao invés de serem analisados "todos os argumentos", o que a jurisprudência vem fazendo não é, senão, dentre os vários fundamentos eventualmente aduzidos, selecionar um em específico que entenda não ser suficiente para acolher o direito pleiteado, desmoronando, assim, todo um castelo lógico construído.

Veja-se que, a depender da matéria debatida, o jurisdicionado pode, de fato, mediante um argumento demonstrar ser detentor de um direito e outro por outro, mais controverso, obter a negativa. A resposta do Judiciário é de justamente selecionar este outro argumento, mais frágil, para denegar o interesse e, com base nos precedentes defensivos, refugiar-se de abordar questões, às vezes, mais polêmicas ou mais trabalhosas.

Esse posicionamento acaba por, em verdade, amedrontar o possível litigante de fazer uso do seu direito ao duplo grau de jurisdição e passa a renegar a efetividade da inafastabilidade da prestação jurisdicional motivada e, mais grave que isso, censura os aplicadores do direito em levantar questões jurídicas mais complexas ou que possam servir de mudança de paradigma no futuro, posto que possivelmente tais argumentos ou serão de plano negados e, assim, abdicada a discussão dos demais argumentos, ou sequer serão analisados, uma vez escorada a jurisdição em ponto que for mais confortável julgar.

Se ousarmos fazer uma comparação com o direito penal, enquanto neste a presunção de inocência é regra aplicada ao réu, no processo civil, a jurisprudência tem adotado uma "presunção de improcedência dos argumentos aduzidos".

Outro ponto de atrito é aquele disposto no inciso VI. Como já salientado, esta disposição funciona como meio de aplicabilidade do sistema de precedentes, de maneira a tornar impositivo ao órgão julgador seguir os entendimentos superiores e, se não o fizer, que isto seja realizado fundamentadamente.

Sobre o disposto no inciso em tela, Eduardo Cambi e Renê Hellman (2018, p. 193), identificam que:

(...) mais uma vez o novo Código de Processo Civil impõe ao julgador o dever de fazer a análise aprofundada dos casos, a comparação das suas características, de modo a justificar a razão de divergir, garantindo a independência e promovendo a efetivação da garantia constitucional do contraditório.

Veja-se que aqui, o que se aplicará não é a mera conclusão dos julgadores no precedente, isto é, não se retirará unicamente o dispositivo de eventual decisão jurisprudencial, mas sim a ratio decidendi extraível de certo julgado.

A ratio decidendi (ou holding no direito anglo-saxão) é a tese decorrente de uma fundamentação decisória em um caso concreto, a qual se desprende do mesmo, de modo a aplicar-se noutras situações jurídicas semelhantes - o que lhe dá o caráter de norma geral (DIDIER JR.; BRAGA; OLIVEIRA, 2017).

O critério para identificar a razão processual deve permear entre os fatos relevantes precursores da causa, bem como os motivos jurídicos determinantes para a conclusão alcançada pelo juízo. Ademais, é elementar que tais critérios embasem o julgamento, sem os quais a consequente disposição seria outra.

Alcançar a razão de um precedente não é, porém, uma tarefa fácil, será imprescindível realizar "a leitura de toda a decisão candidata a precedente, das principais peças do processo que o originou", que será o meio pelo qual se poderá "identificar qual a principal questão que estava sendo solucionada pela corte do precedente e, para tanto, será necessário conhecer o conflito, saber quais as questões de fato e de direito que foram debatidas naquele caso" (FERRAZ, 2018, p. 606).

Daí, aliás, a importância indicada por Teresa Alvim (2016, n.p.) de ser o relatório algo essencial, ao lado da motivação em sentido estrito, da motivação lato sensu. Aquele, devidamente elaborado, possibilita que o segundo grau de jurisdição conheça dos fatos e das teses levantadas, além de ser guia - não cabresto - para que o próprio magistrado possa se manifestar "sobre todas as alegações feitas pelas partes, principalmente, mas não exclusivamente, aquelas cujo exame influi, ou mesmo determina, o teor da parte decisória”. 
Por isso, a aplicação da ratio decidendi não se pode confundir com as "teses firmadas", geralmente entabuladas ao final ou como resultado das decisões, estas são uma abstração de escopo limitado que representam a conclusão alcançada e, embora possam, certas vezes, se confundir com a holding, não demonstram toda a construção processual necessária a ser replicada em casos subsequentes (FERRAZ, 2018).

Feita tal consideração, é de se entender que o juízo deverá (nos termos dos artigos 926 e seguintes do Código) seguir a orientação jurisprudencial superior aplicável ao caso e quando não aplicá-la, incumbirá efetuar a distinção dos casos, desde que seja possível desconstruir no caso concreto os tijolos da norma abstrata que se pretende aplicar, identificando a incompatibilidade entre os fatos e/ ou fundamentos relevantes deste para com o paradigma.

Nesse sentido, tratou o Ministro Edson Fachin nojulgamento do Agravo de Recurso Extraordinário 1.056.101/ES:

positivou o Código de Processo Civil verdadeiro sistema obrigatório de precedentes que naturalmente decorreria da hierarquização do Judiciário e da função da Corte Suprema. Observe-se, no entanto, que essa obrigatoriedade não se traduz por vinculação obrigatória. Juizes e tribunais, ainda que decidam com base na jurisprudência dominante dos Tribunais Superiores, têm o dever de motivação, conforme exige o disposto no art. 489, § 1º do CPC. Dessa forma, devem demonstrar por que o precedente invocado é aplicável ao caso concreto, ou, inversamente, por que se deve realizar uma distinção ou superação do precedente neste mesmo caso concreto. Noutras palavras, o sistema de precedentes explicitado pelo Código de Processo Civil apenas impôs relevante ônus argumentativo a juízes e tribunais quando julgam os casos que assomam a seus órgãos. Esse ônus argumentativo impõe a este Supremo Tribunal Federal um dever de cautela a fim de permitir efetivo diálogo exigido pelo sistema de precedentes. Esse diálogo está na base do sistema de precedentes éé, precisamente, o que permite uniformizar a jurisprudência nacional. Não se pode confundir a mera decisão em sede recursal com o conceito uniformizador do precedente. Há, por isso, um elemento crítico na decisão que se torna precedente (grifos nossos).

Retira-se do posicionamento citado que a vinculação ao precedente não é obrigatória, mas será imperativo observar o sistema de precedentes. Desse modo, se, eventualmente o órgão julgador pretender não seguir jurisprudência invocada pela parte, deverá realizar a técnica do distinguishing e fazê-lo consistentemente (PEIXOTO, 2018).

Outro ponto destacável do voto do Ministro é no que tange à ideia de que Juízes e Tribunais "devem demonstrar por que o precedente invocado é aplicável ao caso concreto".

Com tal afirmação, parece-nos incidir sobre eventual pronunciamento judicial que não cumpra com dito requisito, dois incisos do art. 489, $\$ 1^{\circ}$, do CPC. O primeiro deles é o VI, que tratamos, mas também - apesar de não o estarmos abordando especificamente - o inciso $\mathrm{I}$, o qual indica ser não fundamentada a decisão que "se limitar à indicação, à reprodução ou à paráfrase de ato normativo, sem explicar sua relação com a causa ou a questão decidida".

Nesse caso, partir-se-á de uma interpretação abrangente e homogeneizante dos precedentes. A ratio decidendi a ser eventualmente aplicada em casos compatíveis, tem um caráter de "norma geral", logo, utilizando-se dos critérios de tipicidade legal, sendo encontrada uma hipótese concreta compatível a holding, esta será aplicada por equivalência de seu cabimento.

Trata-se, como explicam Gilmar Mendes e Lênio Streck (2018), de aplicar essa (re)composição da cadeia de decisões precedentes mediante uma coerência interna, não apenas evitando uma contradição, mas ativamente aplicando um juízo equânime. Esta é, senão, a tarefa desafiadora que põe aos juízes: realizar uma aferição isonômica de teses aplicadas a casos semelhantes e antecedentes.

A questão não é meramente reprisar julgados. O debate é de hermenêutica estrutural. O aplicador do direito não pode se prender somente às palavras, mas delas não pode se esquecer. Ele precisa pensar o sistema, não fugir dele. Da mesma forma que, à lei formal, se debateu o papel integrativo do juiz, hoje há de se repensar esta função diante dos precedentes. 
Devemos pensar o precedente de modo retrospectivo e prospectivo (REALE, 1977). Pensando-o para trás, cabe-nos extrair os elementos que ensejaram a tomada de decisão ${ }^{9}$, bem como o sistema onde se insere e, como componente deste, qual função desempenha. Avante, por sua vez, deve-se verificar pragmaticamente os efeitos daquilo que se está a interpretar.

Afinal, se o direito é fato, valor e norma, não é defeso que da norma geral resultante de um precedente, se reavaliem os fatos pretéritos determinantes e os valores que deles se exaravam, para identificar a eficácia no antes e sua reinserção no agora. É esse caráter tridimensional que impõe uma visão dinâmica e estrutural dos precedentes: do ser, surgem e ao ser, retornam (REALE, 1999). Os embargos de declaração podem ser um mecanismo apto para propiciar essa reflexão.

Com efeito, em sentido diverso do que vimos proclamado pelo Min. Fachin, encontram-se nas jurisprudências estaduais verdadeiros mistos decisórios que, fazendo uso de meras passagens de vários julgados, as compilam e transformam em fundamentação. Cite-se, por exemplo, julgado do Tribunal de Justiça do Rio Grande do Sul ${ }^{10}$, ao consignar a seguinte passagem em seu acórdão:

Consoante a firme jurisprudência do Superior Tribunal de Justiça, "A atribuição de efeito suspensivo a recurso especial admitido pelo Tribunal a quo demanda a demonstração inequívoca do periculum in mora, evidenciado pela urgência na prestação jurisdicional, e do fumus boni juris, consistente na possibilidade de êxito do recurso especial, na esteira da jurisprudência uníssona do STJ” (AgRg na MC 23.587/AL, Rel. Ministro BENEDITO GONÇALVES, PRIMEIRA TURMA, julgado em 10/03/2016, DJe 08/04/2016). Nesse sentido, ainda, os seguintes precedentes: AgRg na MC 24.133/DF, Rel. Ministro FELIX FISCHER, QUINTA TURMA, julgado em 05/05/2015, DJe 21/05/2015; AgRg na MC 24.889/CE, Rel. Ministra MARIA ISABEL GALLOTTI, QUARTA TURMA, julgado em 15/12/2015, DJe 18/12/2015; AgRg na MC 24.754/SP, Rel. Ministra LAURITA VAZ, CORTE ESPECIAL, julgado em 07/10/2015, DJe 19/11/2015; AgRg na MC 24.583/PE, Rel. Ministro MARCO BUZZI, QUARTA TURMA, julgado em 15/09/2015, DJe 21/09/2015; AgRg na MC 23.747/SP, Rel. Ministro NAPOLEÃO NUNES MAIA FILHO, PRIMEIRA TURMA, julgado em 08/09/2015, DJe 23/09/2015).

De partida, cumpre sinalizar que não nos deteremos a analisar pormenorizadamente a demanda, nem a matéria debatida, mas convidar a refletir, afinal, uma decisão recheada de julgados que, em tese, lhe dão respaldo, de fato aparenta muita fortaleza, ainda mais se tratando de uma matéria pacificada nas Cortes superiores.

Todavia, em absoluta dissonância ao que se vem expondo, não há qualquer juízo de equanimidade na referida manifestação. Vários são os julgados citados, pouca a reflexão sobre os pressupostos que levaram a Corte a decidir desta ou daquela maneira, ou ainda, com base em um mesmo fundamento, mas sem avaliar o caminho percorrido pelo julgador invocado.

Em verdade, a citada passagem manifesta, com sustentáculo suposta solidez, vicissitude de sua técnica. A um, porque, se compatíveis os pressupostos, não foi realizada a análise necessária para correta aplicação dos precedentes (incidindo o art. 489, §1ํㅡ, I e VI), a dois, porque, se inaplicáveis, eivaria a decisão de vício por força do art. 489, $\$ 1^{\circ}$, III (invocar motivos que se prestariam a justificar qualquer outra decisão).

Ousemos perpassar, agora, um pouco, pelo direito laboral.

Uma ilação se pode extrair daquela seara, quando se fala da aplicação das teorias da acumulação e do conglobamento. Naquela, permite-se o recorte normativo dos dispositivos incidentes à questão, extraindo as partes mais favoráveis de cada um ao trabalhador. Nesta, impõe-se que o julgador deverá selecionar e interpretar qual a norma mais favorável, selecionando uma delas para incidir no deslinde da questão. Esta teoria prevalece, conforme entendimento pacificado do Supremo ${ }^{11}$.

9 Daí, novamente, a relevância elementar do relatório para as decisões.

10 TJ-RS - AGV: 70080617772 RS, Relator: Maria Isabel de Azevedo Souza, Data de Julgamento: 24/04/2019, Câmara da Função Delegada dos Tribunais Superiores, Data de Publicação: Diário da Justiça do dia 26/04/2019

11 Em recente julgado, consignou a Ministra Rosa Weber neste sentido: STF - ARE: 1123539 GO - GOIÁS 000045615.2014.5.18.0201, Relator: Min. ROSA WEBER, Data de Julgamento: 17/04/2018, Data de Publicação: DJe-081 26/04/2018). 
Aliás, também entendível como norma abstrata retirável de um precedente, a ratio decidendi deve ser aplicada de modo conglobante, ou seja, cabe ao julgador decidir pelo precedente melhor (resguardando-se os limites paritários das demandas civis) a se aplicar e, uma vez selecionado, aplicá-lo fundamentadamente, destacando seus fatos e fundamentos jurídicos relevantes.

Afinal, mais vale um precedente bem aplicado que diversos paradigmas desconexos.

Destarte, pode-se retirar deste tópico, que os incisos elencados no art. 489, §1º , de modo especial o IV e o VI, embora trazidos como pressupostos de garantia do devido processo legal, e materializados processualmente através dos embargos de declaração, acabam por ser, de fato rechaçados por uma jurisprudência predominantemente defensiva, que acaba dando um status de "primo pobre" dos recursos aos embargos de declaração.

\section{Conclusão}

É dever do intérprete do direito pensa-lo a partir não só de seus pressupostos basilares, mas reconhecer que existe uma realidade social na qual este se insere, afinal, a própria função do direito reconhece a existência de um ambiente repleto de relações intersubjetivas que necessitam de regulação.

Foi com fulcro neste objetivo que se buscou realizar o presente estudo.

Reconhecer que, hoje, o país sofre com a massificação de demandas, o abarrotamento do Poder Judiciário e a mecanização do debate jurídico-processual é um importante ponto de partida para reconhecer que não só o direito e os jurisdicionados, em si, carecem de olhos mais atentos ao que se tem delineado nas Cortes, mas para esclarecer que a própria atuação da advocacia, como indispensável à administração da justiça que é, nos termos do art. 133, da Constituição, necessita de força para seguir exercendo sua finalidade.

É nesse quadro que envolve a própria legitimação do poder judicante nas mãos do Estado que se fez preponderante destacar dois interesses tão caros à tutela de direitos. A inafastabilidade da jurisdição e o dever de motivação das decisões judiciais, previstos, respectivamente, nos artigos $5^{\underline{o}}$, XXXV e art. 93, IX.

A partir de tais primados, reconheceu-se que ambos são, de um lado, dever do estado e, de outro, direito do jurisdicionado. Essa cognição permite abrir caminho a um debate apto a exaurir as amarras formais do simples direito à provocação do Judiciário e da mera resposta finalista deste mesmo poder.

Incumbe ao Estado, a partir de tais pressupostos, não apenas responder ao cidadão que busca neste terceiro imparcial e estruturado para tanto, mas fazê-lo de modo satisfatório e resolutivo.

Nesse sentido, o Código de Processo Civil de 2015 trouxe novas disposições de cunho axiomático destacando e normatizando pela via infraconstitucional direitos fundamentais, dos quais se destacam a primazia do mérito e a instrumentalidade das formas, sobretudo para permitir que o jurisdicionado alcance, de fato, uma solução razoável para suas lides.

Como princípios que são, contudo, tais normas necessitam de mecanismos jurídicos acessórios que lhes deem efetividade. Sobre estes, destacou-se a função medicinal à ordem processual dos embargos de declaração.

Tal recurso, por força de uma jurisprudência tão engessada e expurgatória, carece muitas vezes da efetividade que lhe é devida.

$\mathrm{O}$ art. 489, $1^{\mathrm{o}}$ em consonância com o dispositivo 1.022, ambos do CPC, mostram-se como verdadeiros instrumentos, respectivamente, de aferição e resolução de vícios processuais do pronunciamento judicante do Estado, de maneira que, se garantida sua consecução, possibilitar-se-á um debate endoprocessual mais saudável, justo e tecnicamente correto.

As previsões do artigo 489, diferentemente do que dispunha o Código anterior, passaram a introduzir nos litígios a imposição aos Juízes e Tribunais de observar o sistema de precedentes, com o fim de permitir que garantir tratamento isonômico entre as partes, dentro e fora do processo. Além 
disso, o legislador buscou garantir aos demandantes o direito de ter as seus argumentos profundamente analisados, o que, no entanto, tem sido de difícil materialização judicial.

É com força nestas razões que nos propusemos a debruçar, e, sobretudo, levantar indagações sobre a temática, para ver se materializar, não apenas na letra fria da lei, mas no âmbito social e judicial, o devido respeito aos direitos de acesso à justiça e de receber, desta mesma justiça, um retorno satisfatório.

\section{Referências}

ALVIM, Teresa Arruda. Embargos de declaração: como se motiva uma decisão judicial. 3. ed. em e-book baseada na $4^{\mathrm{a}}$ ed. impressa. São Paulo: Revista dos Tribunais, 2018. E-book: ISBN 97885-5494752-1.

AURELLI, Arlete Inês. Normas Fundamentais No Código de Processo Civil. In ALVIM, Teresa Arruda; DIDIER JR., Fredie (Org.). Teoria Geral do Processo I: Aplicação das Normas processuais, Princípios Processuais e Competências. v. 1. 2. ed. São Paulo: Revista dos Tribunais, 2018.

BARROSO, Luís Roberto. Curso de Direito Constitucional Contemporâneo: Os Conceitos Fundamentais e a Construção do Novo Modelo. 7. ed. São Paulo: Saraiva, 2018.

CAMBI, Eduardo; HELLMAN, Renê Francisco. Precedentes e Dever de Motivação das Decisões Judiciais. In ALVIM, Teresa Arruda; DIDIER JR., Fredie (Org.). Sentença e Coisa Julgada. v. 5. 2. ed. São Paulo: Thomson Reuters Brasil, 2018.

CANOTILHO, J.J., Direito Constitucional. Coimbra: Almedina, 1993.

CARBONAR, Dante Olavo Frazon. Embargos de Declaração no STJ. In ALVIM, Teresa Arruda; DIDIER JR., Fredie (Org.). Processos nos Tribunais e Meios de Impugnação das Decisões Judiciais. v. 7. 2. ed. São Paulo: Revista dos Tribunais, 2018.

CONSELHO NACIONAL DE JUSTIÇA. Justiça em Números 2018: ano-base 2017. Brasília: CNJ, 2018.

CORDEIRO, Carlos José; GOMES, Josiane Araújo. Motivação das Decisões Judiciais: estudo à luz do art. 489. In ALVIM, Teresa Arruda; DIDIER JR., Fredie (Org.). Sentença e Coisa Julgada. v. 5. 2. ed. São Paulo: Thomson Reuters Brasil, 2018.

DIDIER JR., Fredie; BRAGA, Paula Sarno; OLIVEIRA, Rafael Alexandria de. Curso de Direito Processual Civil. v. 2. 12. ed. Bahia: JusPodvim, 2017.

DIDIER JR., Fredie; CUNHA, Leonardo Carneiro da. Curso de Direito Processual Civil. v. 3. 12. ed. Salvador: JusPodivm, 2017.

FERRAZ, Taís Schilling. Ratio Decidendi X TESE JURÍDICA. In ALVIM, Teresa Arruda; DIDIER JR., Fredie (Org.). Precedentes, Execução, Procedimento Especiais. v. 6. 2. ed. São Paulo: Thomson Reuters Brasil, 2018.

JORGE JUNIOR, Alberto Gossom. Princípios dos Recursos no CPC/2015. In ALVIM, Teresa Arruda; DIDIER JR., Fredie (Org.). Processos nos Tribunais e Meios de Impugnação das Decisões Judiciais. v. 7. 2. ed. São Paulo: Revista dos Tribunais, 2018.

KELSEN, Hans. Teoria pura do direito. São Paulo: Martins Fontes, 1987.

MENDES, Gilmar F.; STRECK, Lênio L. Comentário ao art. 93. In: CANOTILHO, J. J. Gomes; MENDES, Gilmar F.; SARLET, Ingo W.; STRECK, Lênio L. (Coords.). Comentários à Constituição do Brasil. 2. ed. São Paulo: Saraiva Educação, 2018.

MIRANDA, Pontes de. Tratado das Ações: Ação, Classificação e Eficácia / Pontes de Miranda; atualizado por Nelson Nery Junior, Georges Abboud. Tomo I. São Paulo: Editora Revistas dos Tribunais, 2016.

MITIDEIRO, Daniel. Precedentes: Da Persuasão à Vinculação. 2. ed. São Paulo: Editora Revista dos Tribunais, 2017. 
NERY JR., Nelson; NERY, Rosa Maria de Andrade. Código de Processo Civil comentado. 4. ed. em e-book baseada na 18. ed. impressa. São Paulo: Revista dos Tribunais, 2019. E-book: ISBN 97885-5321-747-2.

PEIXOTO, Ravi. O Sistema de Precedentes Desenvolvido Pelo CPC/2015. In ALVIM, Teresa Arruda; DIDIER JR., Fredie (Org.). Precedentes, Execução, Procedimento Especiais. v. 6. 2. ed. São Paulo: Revista dos Tribunais, 2018.

REALE, Miguel. Para uma hermenêutica jurídica estrutural. Revista da Faculdade de Direito, Universidade de São Paulo, v. 72, n. 1, p. 81-91, 1 jan. 1977.

Filosofia do Direito. 19. ed. São Paulo: Saraiva, 1999.

Supremo Tribunal Federal. A Constituição e o Supremo. 5. ed. atual. até a EC 90/2015. Brasília: STF, Secretaria de Documentação, 2016.

THAMAY, Rennan Faria Krüger; ANDRADE, Vinícius Ferreira de. Comentários Sobre a Fungibilidade Recursal. In ALVIM, Teresa Arruda; DIDIER JR., Fredie (Org.). Processos nos Tribunais e Meios de Impugnação das Decisões Judiciais. v. 7. 2. ed. São Paulo: Revista dos Tribunais, 2018.

VAUGHN, Gustavo Fávero. A jurisprudência defensiva no STJ à luz dos princípios do acesso à justiça e da celeridade processual. In ALVIM, Teresa Arruda; DIDIER JR., Fredie (Org.). Teoria Geral do Processo I: Aplicação das Normas processuais, Princípios Processuais e Competências. v. 1. 2. ed. São Paulo: Revista dos Tribunais, 2018.

WAMBIER, Teresa Arruda Alvim. Embargos de declaração. In: WAMBIER, Luiz Rodrigues; WAMBIER, Teresa Arruda Alvim (Coord.). Temas Essenciais do Novo CPC: Análise das principais alterações do sistema processual civil brasileiro. 1.ed. São Paulo: Revista dos Tribunais, 2016. E-book: ISBN 978-85-203-6779-7.Acerca de tais questões, o Fórum Permanente de Processualistas Civis elaborou enunciados que reforçam suas aplicabilidades. Sobre a fungibilidade, o de número $104^{12}$ e quanto à primazia do mérito, o de número $372^{13}$.

12 Enunciado 104: "O princípio da fungibilidade recursal é compatível com o CPC e alcança todos os recursos, sendo aplicável de ofício”. (Grupo: Ordem dos Processos no Tribunal, Teoria Geral dos Recursos, Apelação e Agravo).

13 Enunciado 372: "O art. 4º tem aplicação em todas as fases e em todos os tipos de procedimento, inclusive em incidentes processuais e na instância recursal, impondo ao órgão jurisdicional viabilizar o saneamento de vícios para examinar o mérito, sempre que seja possível a sua correção". (Grupo: Normas fundamentais). 